\title{
Third Meeting of West European Societies of Biological Psychiatry, June 2-4, Berlin, Germany
}

It is our distinct pleasure to welcome you to the $3 \mathrm{rd}$ Meeting of the West European Societies of Biological Psychiatry, taking place on the 2nd to the 4th of June in Berlin, Germany.

This Meeting is organized by the three founding countries, Belgium, France as well as Germany and was extended to Austria and Switzerland. This extension pays tribute to the tradition of the "Drei-Länder-Symposium" organized every fourth year between Switzerland, Austria and Germany. Bringing together these five countries under the roof of the West European Societies of Biological Psychiatry targets for a platform for young scientists performing research in biological psychiatry. We are also pleased to announce that the World Federation of Societies of Biological Psychiatry supports our meeting.

Looking at the overall program of the meeting it was tried to choose themes for the plenary sessions as well as the invited symposia which are currently hot topics in the field. This includes a symposium on "Mirror neurons and empathy", one on "Mania and ADHD: Common pathophysiology, common symptomatology and common treatment" and one on "Neuroplasticity and neuroimmunology in mood disorders". Beside these program highlights our meeting focuses on young researchers and therefore this supplement of the European Archives comprises mainly their work. Based on a thorough review 18 of the 123 submissions were selected to be presented in the oral sessions on Friday afternoon. Out of the presentations three will be selected to receive a prize by the foundation "Nervenheilkunde" of the German Society of Biological Psychiatry. Furthermore there will be a Best Poster Award for each country and a Best Junior Poster.

Apart from the scientific program designed to specifically attract young researchers we are happy to welcome you to the vibrant city of Berlin. It is a city with strong neuroscience and a city open for migrants, new social trends as well as artistic developments.

We do hope you will have a good time enjoying excellent science, leaving space to explore the multifaceted picture of Berlin.

\section{The Meeting Chairs}

Baylé Franck, Paris, France

Dierick Michel, Gent, Belgium

Falkai Peter, Göttingen, Germany

Hatzinger Martin, Basel, Switzerland

Lentner Susanne, Vienna, Austria 